\title{
Knowledge regarding preventive measures of heart disease among the adult population in Kathmandu
}

\author{
Radha Acharya Pandey ${ }^{1^{*}}$, Ismita Khadka ${ }^{2}$ \\ ${ }^{1}$ Department of Nursing, Dhulikhel Hospital, Kathmandu University School of Medical Sciences, Dhulikhel, Kavre; \\ ${ }^{*}$ Corresponding Author: radhapnd@yahoo.com \\ ${ }^{2}$ Dhulikhel Hospital, Kathmandu University Hospital, Dhulikhel, Kavre
}

Received 18 May 2012; revised 17 June 2012; accepted 28 June 2012

\section{ABSTRACT}

Heart disease is the leading cause of death globally. Prevention is the most effective way of combating its epidemic in the resource poor nations. Knowledge on preventive measures of heart diseases has been identified as a prerequisite for change in behavior. This study was conducted with the purpose of identifying the knowledge on heart disease and its prevention among the adults population residing in Dadhikot VDC of Bhaktapur district by interviewing house to house survey. A total of 405 respondents who met the eligible criteria were systematically sampled and interviewed face to face for the study. A pretested Nepali version semistructured interview schedule was used to collect data from adults. The duration of the study was one month i.e. June, 2011. Among total respondents, 57.8 percent had adequate knowledge on heart disease. Only less than half (46.9\%) knew age as non-modifiable risk factor for heart disease followed by hereditary $(39.8 \%)$ and sex (13.8\%). Regarding modifiable risk factors, the most cited response was fatty food consumption (72.6\%) followed by smoking $(70.4 \%)$, stress $(63.7 \%)$, physical inactivity $(61.7 \%)$, hypertension $(59 \%)$, obesity $(58.8 \%)$, high cholesterol diet $(36.5 \%)$ and diabetes (30.1\%). Most of the respondents (57.8\%) knew dyspnea during exertion as symptom of heart disease followed by chest pain (24\%). Majority of respondents $(\mathbf{8 0 . 7 \% )}$ cited decreasing fatty diet as preventive measure of heart disease following daily exercise (75.6\%), eating vegetables and fruits $(71.6 \%)$, keeping blood pressure under control $(59 \%)$ and keeping diabetes under control (33.8\%) respectively. Knowledge was significantly associated with age, gender, education level and family history of heart disease.
Conclusion: The findings concluded that significant percentage (42.2\%) of respondents had inadequate knowledge on heart disease. The findings also highlighted the lack of knowledge on high cholesterol diet and diabetes as modifiable risk factors for heart disease i.e. $36.5 \%$ and $30.1 \%$ respectively. So it is recommended that awareness raising programs could be beneficial on prevention of heart disease is correcting in the deficient areas of knowledge regarding preventive measures of heart disease.

Keywords: Knowledge; Heart Disease

\section{INTRODUCTION}

According to $\mathrm{WHO}$, heart disease especially coronary heart disease is the leading cause of death globally and one of the major health burdens worldwide. Smoking, Dyslipidaemia, Hypertension, Diabetes, obesity, physical inactivity are conventional risk factors. Different studies have shown high prevalence of these risk factors [1]. The prevalence of hypertension in four different geographic regions of Nepal showed highest rate in urban communities of Kathmandu (9.98\%), followed by rural terai, Persaunni (8.11\%), rural hill Kathmandu, Bhadribas (5.98\%), and the mountain region, Jumla (5.3\%). The ten years data of teaching hospital among CAD patients showed $74 \%$ male and $26 \%$ female. Among them $82 \%$ were smokers, $40 \%$ hypertensive, $22 \%$ diabetic, $20 \%$ showed raised LDL and 10\% showed raised triglyceride. In National heart centre Kathmandu CAD (21.7\%) was second most common cause of hospital admission following rheumatic heart disease (29.3\%) in first 300 cases [2].

Progressive urbanization and adoption of a "western" lifestyle contributed to the rising burden of heart disease in the developing world. Developing nations continue to be ill-equipped to handle this burden and this coupled with poor literacy rates and lack of awareness of disease symptoms result in worse disease outcomes. This is re- 
flected in the rising rates of hospital admissions and mortality from heart diseases like CAD at an early age, which in turn inflates the disability adjusted life year (DALYs). Furthermore, People of South Asian descent have one of the highest risks of heart disease in the world [3].

Prevention of heart disease is the most effective way of combating the epidemic in the resource poor nations. Knowledge of modifiable risk factors (smoking, lack of exercise, obesity and consumption of fatty foods) for heart diseases has been identified as a prerequisite for change in behavior and is often targeted by prevention programs. Although knowledge alone is insufficient, it is assumed to be a key component of behavioral change decision making, and provides cues for action. Estimating the level of knowledge of the population at large as well as those suffering from heart disease can help to guide public health programs especially those directed towards reducing modifiable risk factors for heart disease. Earlier studies have revealed that education programs for the elderly were effective in improving health promotion knowledge and behaviors [4].

The level of knowledge of risk factors for heart disease varies among different populations. In the US whites have higher level of knowledge about risk factors of heart disease than others, often disadvantaged groups, such as African Americans. Similarly, in the UK, South Asian families were less likely to take regular exercise, and had a lower awareness of cholesterol or dietary content (fiber, sugar, salt) compared to the native white population. The level of education is one of the predictors of knowledge of healthy life styles. In South Asia the family is often the source of knowledge and awareness of a healthy life style. The traditional extended family household may not be as updated in current knowledge as a nuclear family household because of a more standard attitude to health beliefs [5].

A study on the risk factors for heart disease has shown that tobacco use, ghee intake, raised fasting glucose, high cholesterol, paternal history of heart disease, low income, and low levels of education are associated with premature myocardial infarction in Pakistan [6].

\section{METHODOLOGY}

This is a cross-sectional study. A face to face interview survey method using structured questionnaire was adopted for this survey.

\section{STUDY SITE AND STUDY POPULATION}

Study population consisted of Adult (19 - 65 years) population residing in Ddhikot Village Development Committee (VDC) Bhaktapur and who were present at the time of data collection. A semi-structured interview schedule consisting of questions related demographic characteristics and awareness items related to heart disease developed by reviewing literature. The content validity of the instrument was established seeking opinion of cardiologist consultant and related nursing teacher. The instrument was then translated into Nepali language and opinion of language expert was obtained for comprehensibility and simplicity of language and for consistency of the content. The instrument was pretesting on $10 \%$ similar adults from same VDC ward no. 6 .

\subsection{Ethical Consideration}

The study was conducted after obtaining approval from the concern authority at KUSMS. Prior to collecting data, administrative approval was obtained from the Chairman of Dadhikot VDC.

The study respondents were adequately informed and explained about the purposes of the study. They were assured of the privacy and confidentiality of the information. So, verbal informed consent was obtained before a respondent was interviewed which is quite common in previous study too.

Stratified sampling technique was used for selection of 4 wards (1, 7, 8 \& 9) among 9 wards of Dadhikot VDC. Systematic sampling technique was used for selection of households from each ward.

Data was collected by the researcher herself by interviewing the eligible adults $(n=405)$ through house to house visit. All adults who met the criteria, who were available during data collection and who gave informed consent were interviewed.

\subsection{Data Analysis}

The collected data were reviewed daily for completeness and accuracy. Edited data were entered into the Statistical Package for Social Science Software (SPSS) version 16.0 for statistical analysis using descriptive statistics. The Demographic characteristics of the adults are presented in Table 1 and in Tables 2-7 were about knowledge regarding preventive measures of heart disease and knowledge association with different variables.

\section{RESULTS}

Among 405 respondents, $36.8 \%$ of the total respondents falls under $<30$ years group which is the largest age group, other age groups 30 - 39 years, 40 - 49 years and $>49$ years comprises $20.7 \%, 20.7 \%$ and $21.7 \%$ respectively. Regarding gender of the respondents, $51.1 \%$ were female.

Regarding educational level, $19.5 \%$ of respondents were illiterate, only $21 \%$ held secondary level followed 
Table 1. Demographic information of the respondents $(n=$ 405).

\begin{tabular}{|c|c|c|c|}
\hline Variables & & Frequency & Percentage (\%) \\
\hline \multirow{4}{*}{$\begin{array}{l}\text { Age in } \\
\text { years }\end{array}$} & $<30$ & 149 & 36.8 \\
\hline & $30-39$ & 84 & 20.7 \\
\hline & $40-49$ & 84 & 20.7 \\
\hline & $>49$ & 88 & 21.7 \\
\hline \multirow{2}{*}{ Gender } & Male & 198 & 48.9 \\
\hline & Female & 207 & 51.1 \\
\hline \multirow{6}{*}{$\begin{array}{l}\text { Education } \\
\text { level }\end{array}$} & Illiterate & 79 & 19.5 \\
\hline & $\begin{array}{l}\text { Informal } \\
\text { education }\end{array}$ & 67 & 16.5 \\
\hline & Primary level & 55 & 13.6 \\
\hline & Secondary level & 85 & 21.0 \\
\hline & $\begin{array}{l}\text { Higher } \\
\text { secondary level }\end{array}$ & 43 & 10.6 \\
\hline & $\begin{array}{l}\text { Bachelor or } \\
\text { above level }\end{array}$ & 76 & 18.8 \\
\hline \multirow{6}{*}{ Occupation } & Agriculture & 128 & 31.6 \\
\hline & Service/Job & 56 & 13.8 \\
\hline & Business & 86 & 21.2 \\
\hline & Student & 71 & 17.5 \\
\hline & Housewife & 54 & 13.3 \\
\hline & Others & 10 & 2.5 \\
\hline
\end{tabular}

by bachelor or above (18.8\%). Among the total respondents, $31.6 \%$ were involved in agriculture, less than one quarter $(21.2 \%)$ were involved in business, only $17.5 \%$ of respondents were students (Table 1).

Among 405 respondents, only $46.9 \%$ knew age as risk factor for heart disease followed by hereditary (39.8\%) and least identified non-modifiable risk factor was sex (13.8\%).

Regarding modifiable risk factors, the most cited response was fatty food consumption $(72.6 \%)$ followed by smoking and tobacco use (70.4\%), stress (63.7\%), physical inactivity $(61.7 \%)$, high blood pressure (59\%), obesity $(58.8 \%)$, high cholesterol diet $(36.5 \%)$ and diabetes (30.1\%) (Table 2).

Regarding sign and symptoms, majority of respondents $(57.8 \%)$ cited shortness of breathing during exertion as symptom of having heart disease, $48.6 \%$ reported heart disease can be asymptomatic. Among Total respondents, only $68.1 \%$ knew heart disease as preventable disease.

Among the total respondents, majority of them (80.7\%) identified decreasing fatty diet as preventive measure of
Table 2. Knowledge regarding modifiable \& non-modifiable risk factors of heart disease $(n=405)$.

\begin{tabular}{lll}
\hline \multicolumn{1}{c}{$\begin{array}{c}\text { Non-modifiable } \\
\text { risk factors }\end{array}$} & Frequency & Percentage (\%) \\
\hline Age & 190 & 46.9 \\
Hereditary & 161 & 39.8 \\
Sex & 56 & 13.8 \\
Modifiable risk factors & & \\
Fatty food consumption & 294 & 72.6 \\
Smoking and tobacco use & 285 & 70.4 \\
Stress & 258 & 63.7 \\
Physical inactivity & 250 & 61.7 \\
High blood pressure & 239 & 59 \\
Obesity & 238 & 58.8 \\
High cholesterol diet & 148 & 36.5 \\
Diabetes & 122 & 30.1 \\
\hline
\end{tabular}

Table 3. Knowledge regarding symptoms \& preventive measures heart disease $(n=405)$.

\begin{tabular}{lll}
\hline Sign and symptoms & Frequency & Percentage (\%) \\
\hline $\begin{array}{l}\text { Shortness of breathing during } \\
\text { exertion }\end{array}$ & 234 & 57.8 \\
Asymptomatic & 197 & 48.6 \\
Chest pain & 97 & 24.0 \\
Heart disease is preventable & & \\
Yes & 276 & 68.1 \\
No & 50 & 12.3 \\
$\begin{array}{l}\text { Don't know } \\
\text { Preventive measures }\end{array}$ & 79 & 19.5 \\
$\begin{array}{l}\text { Decreasing fatty diet and } \\
\text { having balanced diet }\end{array}$ & 327 & 80.7 \\
$\begin{array}{l}\text { Daily physical exercise } \\
\text { Eating vegetables and fruits }\end{array}$ & 306 & 75.6 \\
$\begin{array}{l}\text { Keeping blood pressure under } \\
\text { control }\end{array}$ & 290 & 71.6 \\
Keeping diabetes under control & 137 & 59.0 \\
\hline
\end{tabular}

heart disease. Most of them (75.6\%) knew daily physical exercise is helpful for preventing heart disease. The correct responses for eating vegetables and fruits and keeping blood pressure under control for prevention of heart disease were $71.6 \%$ and $59 \%$ respectively (Table 3).

The knowledge regarding preventive measures of heart disease in $<30$ years is more than $\geq 30$ years. The 
differences seen in these two age group is statistically significant $(\mathrm{p}=0.002)$. Odd ratio was 1.95 (Table 4).

The knowledge in male is $65.7 \%$ whereas female is $50.2 \%$. The differences seen in these gender is statistically significant $(\mathrm{p}=0.002)$. Odd ratio was 1.89 (Table 5).

The knowledge in illiterate is $22.8 \%$ whereas in literate is $66.3 \%$. The differences seen in these two education level is statistically significant $(\mathrm{p}=0.000)$. Odd ratio was 0.15 (Table 6).

The knowledge among the respondents having family history of heart disease is $70.8 \%$ whereas on those without family history of heart disease is $55.3 \%$. The differences seen in these two group is statistically significant $(p=0.026)$. Odd ratio was 1.96 (Table 7).

\section{DISCUSSION}

This study was carried out to assess the existing knowledge regarding preventive measures of heart disease (Coronary Heart Disease) among the adult population of a community as well as its association with dif- ferent variables. The discussion was made by reviewing different literature regarding knowledge of heart disease which directly or indirectly supports this study. The objectives of the study were:

Among the total respondents, $97.5 \%$ had heard about heart disease and only $2.5 \%$ are unaware about it. Maximum proportion of respondents (78.5\%) obtained information related to heart disease from television, which is similar to the study conducted by Philip (2005) that showed television was highest source of information. So, television can be used as a good source of information for providing awareness programme [5].

The results indicate that the majority $(60.2 \%)$ of individuals had adequate knowledge on modifiable risk factors of heart disease. However, significant percentage of respondents $(39.8 \%)$ lacked the adequate knowledge of modifiable risk factors contributing to heart disease. This result is not consistent with the study conducted at Karachi that showed $42 \%$ respondents to have adequate knowledge [6]. However, the most identified modifiable risk factors in both studies were fatty food consumption

Table 4. Associations between knowledge and age of the respondents $(n=405)$.

\begin{tabular}{cccccc}
\hline \multirow{2}{*}{ Age } & Knowledge Regarding Preventive Measures of Heart Disease & & p value & Odd Ratio \\
\cline { 2 - 3 } & Adequate & Tnadequate & & \\
\hline$<30$ years & $101(67.8 \%)$ & $48(32.2 \%)$ & 149 & 0.002 & $\mathbf{1 . 9 5}$ \\
$\geq 30$ years & $133(52 \%)$ & $123(48 \%)$ & 256 & \\
\hline
\end{tabular}

Table 5. Associations between knowledge and gender of the respondents $(n=405)$.

\begin{tabular}{cccccc}
\hline \multirow{2}{*}{ Gender } & Knowledge Regarding Preventive Measures of Heart Disease & & p value & Odd Ratio \\
\cline { 2 - 3 } & Adequate & Inadequate & & \multirow{2}{*}{0.002} \\
\multirow{2}{*}{ Male } & $130(65.7 \%)$ & $68(34.3 \%)$ & 198 & $\mathbf{1 . 8 9}$ \\
Female & $104(50.2 \%)$ & $103(49.8 \%)$ & 207 & \\
\hline
\end{tabular}

Table 6. Associations between knowledge and education of the respondents $(n=405)$.

\begin{tabular}{cccccc}
\hline \multirow{2}{*}{ Education Level } & Knowledge Regarding Preventive Measures of Heart Disease & & \multicolumn{2}{c}{ p value } & Odd Ratio \\
\cline { 2 - 3 } & Adequate & Total & & \multirow{2}{*}{0.000} \\
Illiterate & $18(22.8 \%)$ & $61(77.2 \%)$ & 79 & $\mathbf{0 . 1 5}$ \\
Literate & $216(66.3 \%)$ & $110(33.7 \%)$ & 326 & \\
\hline
\end{tabular}

Table 7. Associations between knowledge and family history of heart disease $(n=405)$.

\begin{tabular}{cccccc}
\hline \multirow{2}{*}{ Family History of Heart Disease } & \multicolumn{2}{c}{ Knowledge Regarding Preventive Measures of Heart Disease } & & \multirow{2}{*}{ p value } & \multirow{2}{*}{ Odd Ratio } \\
\cline { 2 - 4 } & Adequate & Inadequate & & \\
\cline { 2 - 4 } Yes & $46(70.8 \%)$ & $19(29.2 \%)$ & 65 & 0.026 \\
No & $188(55.3 \%)$ & $152(44.7 \%)$ & 340 & \\
\hline
\end{tabular}


and smoking.

In a study conducted at New Delhi, 68\%, 72\%, 73\% and $57 \%$ of the respondents identified smoking, obesity, hypertension, and high cholesterol correctly, respectively. $30 \%$ identified diabetes mellitus as a modifiable risk factor of CHD [4]. It shows the consistency with this study which showed $70.4 \%$ and $30.1 \%$ respondents to have knowledge on smoking and diabetes as risk factor for heart disease respectively. However, the results regarding knowledge on hypertension (59\%) and obesity $(58.8 \%)$ as modifiable risk factors of heart disease is not consistent with the above study.

Regarding preventability of heart disease only $68 \%$ were aware of heart disease as preventable disease. This is similar to the survey carried out at China, where three quarters of participants did not regard heart disease as preventable disease [7].

In this study the knowledge is compared with the variables such as age, gender, education, and family history of heart disease. It was found that males had significantly higher knowledge compared to females. This difference could be due to the fact that males usually had more opportunity to education, interaction and socialization than females. This holds particularly well for country such as Nepal where traditional norms and customs discriminate against females. However, the finding is not similar to the findings of the study conducted by Almas (2008) which showed no significant association between gender and knowledge [8].

Regarding age, $<30$ years of age had better knowledge than $\geq 30$ years of age. This is because younger people were students and they had more knowledge regarding heart disease.

Considering the influence of education on knowledge, it was found that literate respondents had higher knowledge than illiterate. Similar effect was observed in a study conducted by Muhammad et al., where level of education had significant influence on knowledge [6].

The study concluded that there was significant association between accessibility to information on heart disease and knowledge, which is similar to the findings of the survey conducted by Ms Khajeeda Abdulla (2008) [9]. The association was also seen between family history of heart disease and knowledge regarding preventive measures of heart disease. The finding was consistent with the similar research done in Pokhara by Shankar et al., which showed that there was significant relation between knowledge on heart disease with family history of heart disease [10] This may be because of the respondents with self/family members suffering from heart disease would have had a strong motivation to know more about these condition.

\section{THE LIMITATIONS OF THE STUDY}

The result of the study does not represent the whole population because it is a small scale community based study limited to the population in selected wards of Dadhikot VDC during the short period of data collection.. Hence the results may not be generalized.

\section{CONCLUSIONS}

Heart disease is a significant problem among adult population in Nepal although it is preventable. So assessing the knowledge regarding preventive heart disease could be the effective measure to prevent heart disease.

Based on the findings, it is concluded that the that there is significant percentage $(42.2 \%)$ of respondents were having inadequate knowledge regarding preventive measures of heart disease,

Similarly, majority of respondents correctly identified fatty food consumption as modifiable risk factors of heart disease. There was association between the knowledge and selected variables (age, gender, education level, family history of heart disease and accessibility to information).

Heart disease is the leading cause of morbidity among middle adulthood. Attention need to be paid more in the intensive planning of educational programme on deficient areas of knowledge for prevention of heart disease.

\section{REFERENCES}

[1] Nishtar, S. (2002) Prevention of coronary heart disease in South Asia. The Lancet, 360, 1015-1018. doi:10.1016/S0140-6736(02)11088-9

[2] Maskey, A., Sayami, A. and Pandey, M.R. (2003) Coronary artery disease: An emerging epidemic in Nepal. Journal of Nepal Medical Association, 42, 122-124. http://www.jnma.com.np/

[3] Chan, C.W and Chung, J.W.Y. (2011) A survey of coronary heart disease knowledge in a sample of Hong Kong Chinese. Asia-Pacific Journal of Public Health, 23, 288297. doi:10.1177/1010539509345869

[4] Saeed, H., Omer, T., Sharma, K. and Gupta, P. (2009) Knowledge of modifiable risk factors of coronary atherosclerotic heart disease (CASHD) among a sample in India. http://ukpmc.ac.uk/abstract/MED/1919231

[5] Philip, S. (2005) A study to assess the knowledge level regarding risk factors contributing to coronary heart disease (muncipal workers) of bangolare attending the preventive cardiology centre of Corporation Hospital. http://119.82.96.198:8080/jspui/bitstream/123456789/137 6/1/CDNNMSN00050.pdf

[6] Muhammad, S.K. et al. (2006) Knowledge of modifiable risk factors of heart disease among patients with acute myocardial infarction in Karachi, Pakistan: A cross sectional study.

http://www.biomedcentral.com/1471-2261/6/18

[7] Chen, C.W. (2008) Knowledge and attitude of coronary heart disease prevention among middle and older aged 
people in a community in Taipei, China. http://www.tagg.org.tw/down/B1-P251-262.pdf

[8] Almas, A. (2008) Knowledge of coronary artery disease (CAD) risk factors and coronary intervention among university students. http://www.ncbi.nlm.nih.gov/pubmed/18998308

[9] Khajeeda, A. (2008). Accessibility to knowledge and information on risk factors and prevention of cardiovas- cular disease and preventive behavious of residents. http://www.cphs.chula.ac.th/J\%20Health\%20Res/files/Fu 11Text/23/Supplement/Khadeeja.pdf

[10] Shankar, P.R. et al. (2007) Knowledge about heart attack and hypertension among individuals attending a cardiac camp in Pokhara City. Kathmandu University Medical Journal, 5, 273-278 